\title{
Research Paper: Picture Naming in Children With and Without Specific Language Impairment: An Error Analysis Study
}

\author{
Fatemeh Hassanati $^{1,2}$, , Reza Nilipour ${ }^{1}$, Zahra Sadat Ghoreishi ${ }^{1 *}$,, Abbas Pourshahbaz $^{3}$ Mohammad Momenian $^{4}$ \\ 1. Department of Speech Therapy, University of Social Welfare and Rehabilitation Sciences, Tehran, Iran. \\ 2. Student Research Committee, University of Social Welfare and Rehabilitation Sciences, Tehran, Iran. \\ 3. Department of Clinical Psychology, University of Social Welfare and Rehabilitation Sciences, Tehran, Iran. \\ 4. Laboratory for Communication Science, Division of Speech and Hearing Sciences, Faculty of Education, University of Hong Kong, Kowloon Tong, \\ Hong Kong.
}

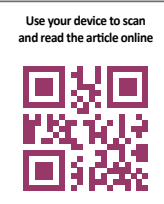

Citation: Hassanati F, Nilipour R, Ghoreishi ZS, Pourshahbaz A, Momenian M. Picture Naming in Children With and Without Specific Language Impairment: An Error Analysis Study. Iranian Rehabilitation Journal. 2018; 16(3):289-296. http://dx.doi. org/10.32598/irj.16.3.289

http://dx.doi.org/10.32598/irj.16.3.289

\section{(c) (1) (8)}

Funding: See Page 294

Article info:

Received: 05 Apr 2018

Accepted: 02 Aug 2018

Available Online: 01 Sep 2018

\section{Keywords:}

Child, Specific language impairment, Data accuracy, Reaction time, Word processing

\section{ABSTRACT}

Objectives: The lexical-level deficits are one of the hallmark limitations observed in early school-age children with specific language impairment. These problems are the predictors of reading problems and poor performance at school. Most studies in Persian-speaker children with specific language impairment have focused on syntax and morphology and the naming errors profile of these children are overlooked. This study aimed to investigate the naming accuracy, latency, and the error profile of these children.

Methods: This was an observational study. Twenty children with specific language impairment were selected according to the clinical judgment of two speech therapists from speech therapy clinics and 100 children with typical language development aged from 7 to 9 years were randomly selected from public schools. The Persian picture naming set was presented by DMDX for the examination of picture naming skills. Naming errors were categorized as semantic, formal, mixed, non-word, unrelated, and others errors. Then, the data were investigated in terms of descriptive statistics and analysis of differences by the Independent $t$ test and Mann-Whitney U test.

Results: The Persian-speaker children with specific language impairment name significantly slower and less accurate than the children compared to children with normal language development $(\mathrm{P} \leq 0.05)$. Although semantic errors were the most frequent errors in the two groups, the score differences of formal and omission errors were significant between the groups $(\mathrm{P} \leq 0.05)$

Discussion: The different naming accuracy and latency scores between the two groups may be due to language delay and the inefficiency of the semantic system in children with specific language impairment. There are a variety of word retrieval errors in Persian-speaker children. Although, there are differences between the two groups, the error type in picture naming cannot be used for differentiating between them.

* Corresponding Author: 


\section{Highlights}

- The naming skill in children with specific language disorder (SLI) is slower and less accurate than children with normal language development.

- The semantic errors are the most common errors in both normal children and children with language disorder.

- The formal and omission errors could differentiate between normal children and children with language disorder.

- Picture naming is a useful test for determining the word retrieval skills in children with and without language disorder.

\section{Plain Language Summary}

Language delays or disorders result in significant and often ongoing problems for children. A common outcome is less development of semantic representations of children with word finding difficulties. This makes retrieval skill inaccurate, slow, or wrong. The studies of naming skill in children with specific language disorders indicate significantly slower and less accurate naming processes in different languages. In the present study, the naming skill in children with specific language disorder are found to be slower and less accurate which maybe because of either a less developed language system or a delay in vocabulary development. In addition, the types of errors in children with and without language disorder are the same but the number of each error is different. In conclusion, the researchers and the therapist can use the picture naming task for determining the word retrieval problems.

\section{Introduction}

pecific Language Impairment (SLI) is a developmental language disorder in which children exhibit unexpected problems in learning speaking skill [1]. Children with SLI have difficulties in language comprehension, language production, or both in the absence of hearing impairment, a general developmental delay, any neurological impairments, and autism spectrum disorders, whilst the nonverbal IQ score is normal [2]. SLI is higher in males and its prevalence rate is about 7\% [3].

Limitations in the language abilities of children with SLI is found in all language domains, from basic levels such as lexicon, syntax, and morphology to the advanced levels of language like narrative structure [4, 5]. Previous studies showed that children with SLI have limited lexicon. Also, word-finding problems is another limitation that has been reported for children with SLI $[6,7]$. These children lack a quick and proper ability to retrieve a known word from their mental lexicon. Word-finding difficulties are predictors of reading problems and poor performance at school [8]. Therefore, investigating naming retrieval in children with language impairment is essential.

Picture naming can be characterized by a 3-stage process in adults [9]. First, object identification, then the activation of a set of lexical candidates or lemmas and the selection of the target lemma. Finally, more activation of phonological information at the lexeme-level [10]. This process must occur rapidly and efficiently in fluent speech [9].

Several studies recognized the lemma level as a cause of naming errors (especially semantic errors) [8]. McGregor et al. (2002) believed that naming errors are the result of less semantic representations. They compared naming skills in 16 children with Typical Language Development (TLD) and 16 children with SLI and found that the "semantic errors" and "without answer" were the most common errors, in both groups. Their findings suggested that sparse semantic representations would result in naming failures in both groups [11]. On the other hand, some authors believe that lexeme-level takes part in naming processes and retrieval, more than lemma lev$\mathrm{el}$, as a cause of naming errors (especially formal errors) [8]. In addition, some studies report that slower speed of processing is the cause word finding difficulties, especially in more complex semantic stimuli [6]. Children with SLI take a longer time to retrieve names than their peers, for correct naming [8].

A lot of attention has been paid to naming errors in children with SLI. Lahey and Edwards (1999) compared naming errors in children with SLI and in normally developing children using 56 pictures of familiar objects. 
Children with SLI made more errors than their peers. Phonological errors were considered as an evidence for deficits in phonological processing and representation whereas semantic errors provided the evidence of sparse and poorly organized semantic representation [12].

Kambanarosan and Grohmann (2010) compared object and action picture naming between 30 children with TLD, aged 6;0-6;11 years, 7 children with SLI, aged 6;411;0 years, and 13 children with word finding difficulty, aged 6;3-11;11 years. Children with SLI significantly produced more errors compared to the adults. Also, omission errors were predominant response to object picture naming in children with SLI [13].

Researchers have mostly focused on morphosyntax, phonology, and pragmatics in children with SLI [8]. Thus, developmental research on lexical domain and specifically difficulties in retrieving lexical items is relatively scarce. The Persian language consists of 23 consonants and six vowels and all words begin with a consonant [14]. In Persian, nouns have more simple structure than verbs, therefore, nouns can be learned easily [15].

The present study aimed to examine the naming accuracy and latency as well as errors with reference to the specific psycholinguistic models of lexical/word processing, also to determine whether error types differentiate children with SLI from peers with TLD.

\section{Methods}

\section{Study participants}

This was a descriptive- analytical study. Twenty 7 to 9 years old children with SLI ( 8 girls and 12 boys, with the mean age of 8.1 years) and 100 children with TLD (50 girls and 50 boys, with the mean age of 8.4 years) aged 7 to 9 years as the control group participated in this study. For enrolling normal children, at first 15 public schools in Tehran, Iran were randomly chosen from 3 regions according to the socioeconomic status. Then the children were selected with regards to the inclusion criteria. The inclusion criteria consisted of being monolingual native Persian speaker; lacking any language disorders; and being healthy with normal hearing, intelligence, and sensory-motor ability. Children with SLI were monolingual and of middle sociocultural class, from regular schools. The children with SLI were recruited via the speech and language centers in Tehran. We used clinical judgment as the reference standard to diagnose children with SLI [16].
Two professional Speech-Language Pathologists (SLPs) examined the children. First, the qualified children with language impairment were screened $(n=250)$, and those who passed screening were selected for the main assessment phase. Twenty percent $(n=50)$ of children passed the screening and were selected for the assessment. Children with SLI were diagnosed according to the following criteria by 2 SLPs: lack of any speech and communication disorders such as autism or stuttering, parents' report on normal development of their children in all developmental fields excluding language, normal nonverbal IQ scores (we used Raven's Colored Progressive Matrices Test) [17], no hearing impairment according to the pure tone audiometry test, and lack of evident emotional and behavioral problems like autism spectrum disorders or history of evident neurological disorders.

The two last criteria were examined by a parent questionnaire including personal, medical, social, educational and developmental information. Finally, the informal motor assessment demonstrated intact motor speech ability. The language abilities of children were examined via the Test of Language Development in Persian (TOLD-P:3). Its normalized data and the Persian Test of Specific Language Impairment are available for Persianspeaking children [18]. This test consists of a sample spontaneous speech and the description of picture series, word and non-word repetition, and grammar parts. This can be considered as clinical SLI markers in the Persian language [19]. The internal consistency was measured using Cronbach $\alpha$ value which was 0.90 for 60 children aged 5-10 years old [20]. In total, $40 \%$ of the children $(n=20)$ were diagnosed with SLI.

\section{Study materials}

The Persian picture naming set was used for this study. This set includes 128 simple black and white pictures and normalized data for naming latency and psycholinguistic factors (Age of Acquisition [AoA], familiarity, visual complexity, and name agreement) for 7- to 9-year-old Iranian children. The Persian picture naming set includes data on the name agreement (the proportion of participants who used the expected name, and the Hvalue based on the number of possible names), familiarity (measured by a 3-point scale in which 1 is defined as unfamiliar, 3 as moderately familiar, and 5 as very familiar), visual complexity (measured by a 3-point scale in which 1 indicates easy, 3 indicates moderately easy, and 5 indicates difficult), AoA (using a 9-point scale with $1=$ under 1 year of age , $2=1$ years old, up to $9=8$ years old or older, according to the parents' reports) [21]. The 
normalized data of the Persian picture naming set and the number of subjects for each part are listed in Table 1.

\section{Study procedure}

Picture naming set (including 128 pictures) was displayed by DMDX software. DMDX is a software for analyzing the experimental/control group variables and timing of stimulus display. It is a program that can run psychological experiments in healthy and impaired populations. DMDX presents the lists of stimuli (pictures, text, sounds) and saves the reaction times and correct and error responses in a data file for later analysis [22].

Both groups of children were placed individually, in front of a laptop connected to a microphone. The child was instructed to name the pictures quickly, with one word, without using extra words or voices. Firstly, five experimental pictures were shown to the child. When the examiner made sure that the child had understood the procedure, the target pictures were presented. In addition to recording the voice by the software with microphone, the examiner wrote down the name produced by the child, as each child responded. Each picture was presented to the child for $5000 \mathrm{~ms}$ [23]. A time interval of $1000 \mathrm{~ms}$ was considered between each two pictures [24]. All tests were divided in four blocks and were randomly presented to the child, with the child receiving breaks between the blocks. Each participant was tested in one session usually lasting from 30 to 45 minutes.
The error types were first categorized by the first author and later recategorized by another SLP. Disagreements between the two SLPs were resolved by one assistant SLP. Dell, Schwartz, Martin, Saffran, and Gagnon (1997) generated six different error-types in picture naming. Semantic errors are superordinate, coordinative, associative, or subordinate semantic substitutions of the target word and synonyms. Formal errors are real words that contain a phonological feature of the target word Mixed errors are real words that are related semantically and phonologically. Unrelated errors are real word errors that are not related semantically or phonologically to the target item. Non-word errors are responses that are not real words. The 'other' category is used for all other responses, such as description and 'don't knows' [25].

\section{Statistical analysis}

The descriptive (mean score and standard deviation, etc.) and inferential statistical analysis (the Independent t-test or Mann-Whitney U test) methods were used.

\section{Results}

Naming latency was calculated only for correct names, recorded by DMDX. In the SLI group, $26.3 \%$ of the responses were incorrect and $8.12 \%$ were not recorded by the software, and the error responses by the children with TLD were $12.24 \%$, and $8.02 \%$ were not recorded by DMDX program that were excluded from the analy-

Table 1. Psycholinguistic features of picture naming set in Persian-speaking children

\begin{tabular}{cccccc}
\hline \multirow{2}{*}{$\begin{array}{c}\text { Statistical } \\
\text { Variables }\end{array}$} & \multicolumn{2}{c}{ Name Agreement } & & & \\
\cline { 2 - 5 } & $(\%)$ & $(H)$ & Conceptual Familiarity & Visual Complexity & AoA (Mon) \\
\hline No. & 100 & 100 & 30 & 30 & 30 \\
\hline Mean & 86.09 & 0.33 & 3.67 & 2.32 & 27.22 \\
\hline SD & 17.10 & 0.45 & 1.23 & 0.91 & 5.85 \\
\hline Maximum & 100 & 2.20 & 5 & 4.60 & 42 \\
\hline Minimum & 31 & 0.00 & 1.20 & 1.00 & 11.60 \\
\hline
\end{tabular}

Abbreviations: H: H-value, AoA: Age of Acquisition, SD: Standard Deviation.

Iranian Rehabilitation Journal

Table 2. Mean picture-naming accuracy and latency for the Iranian children with TLD and SLI aged 7-9 years old

\begin{tabular}{cccc}
\hline Variables & TLD & SLI & P \\
\hline Latency (ms) & 1399.8 & 1567.4 & $\leq 0.000$ \\
Accuracy (\%) & 85.2 & 73.7 & $\leq 0.001$ \\
\hline
\end{tabular}


Table 3. Mean \pm SD error proportions score and standard deviation for children with TLD and SLI aged 7-9 years

\begin{tabular}{cccc}
\hline Errors & TLD & SLI & P \\
\hline Semantic & $11.2 \pm 5.37$ & $0.05 \pm 4.8$ \\
Formal & $0.07 \pm 0.03$ & $0.47 \pm 0.05$ & $0.000^{\#}$ \\
Unrelated & $0.28 \pm 0.06$ & $0.35 \pm 0.08$ & $0.64 \pm 7.1$ \\
Others & $4.3 \pm 4.00$ & $5.09^{\#}$ \\
Omission (one type of others error) & $3.2 \pm 0.7$ & $0.03^{\#}$ \\
\hline
\end{tabular}

*: Independent t test. ": Mann-Whitney U test. The data are presented as Mean£SD.

Iranian Rehabilitation Journal

sis. We controlled the outliers in naming latency and then normality of the data was examined by the Shapiro-Wilk Test. Table 2 presents the naming latency and accuracy in children with and without SLI.

The results of Independent $t$ test showed that children with TLD were more accurate and faster in picture naming than children with SLI. Also, there were significant differences in naming accuracy and latency between the two groups.

Error profiles in picture-naming were created for the proportion of the 6 error types (semantic, formal, mixed, non-word, unrelated, and other). An average error profile was created for each group by calculating the mean score of each error type proportion. Statistical analyses were not conducted for mixed and non-word errors because the number of errors per these conditions were very small in children with SLI and there was no error in children with TLD. Initially, the descriptive statistics were analyzed. Then, the normal distribution of population was determined by the Shapiro-Wilk Test. Finally, the parametric and non-parametric tests were performed. The error analysis for the two groups of children are listed in Table 3.

Table 3 indicates that the number of errors in children with SLI was higher than children with TLD, but the mean score of formal and omission errors were significantly different between the two groups $(\mathrm{P} \leq 0.05)$. Furthermore, the number of semantic errors were higher than other errors in both groups, but the differences between the two groups were not significant $(P \geq 0.05)$.

\section{Discussion}

The present study aimed to compare the naming accuracy and latency in 7- to 9-year-old Persian speaking children with and without SLI to determine their profile errors in the picture naming task. Consistent with previ- ous studies, our results revealed that the children with SLI were also less accurate and slower than their peers in picture naming [26-29]. Children with SLI may have slow language development in general and underdeveloped semantic representation in particular $[11,30]$.

Children with SLI are less able to learn semantic features and lexical labels of new words than age-matched peers, suggesting less complete mapping in the beginning stage of word learning [31]. Therefore, the high rate of naming errors in the studied children with SLI suggests problems in extended mapping. Also, these children show difficulties in long-term memory retrieval, leading to longer naming retrieval and more naming errors $[32,33]$. In line with prior research, the present study showed children with SLI take a longer time to retrieve names than their peers, even when correctly perform naming [26, 28, 34].

Error profile revealed that children with SLI have more errors compared with TLD. Consistent with previous studies, the semantic errors were the most common type of errors in both children with TLD and SLI, [6, 30, 32]. Also, the omission error (don't know) was seen in children with SLI. According to the models of adult lexical production, the lemma level involves the processing of semantic information [10]. It is assumed that incomplete semantic representations are likely to result in semantic errors and the lack of semantic representation results in omission errors. Semantic errors arose when the target word node was relatively unavailable, and consequently, semantically related words were activated and produced instead of the target name [13].

According to the language development in children, especially in children with SLI, insufficient information in semantic memory caused by language difficulties may result in retrieving the semantically alternative names instead of the target name $[8,26,32,35]$. As a result, both semantic and omission errors are often associated 
with limited semantic representation, which involves both missing and sparse representations. In addition to the absent or sparse semantic representation at the level of lemma selection, there are other sources of naming errors such as misperception of the picture stimuli at the level of object recognition, lack of links between semantic representations to retrievable phonological input and output forms [35], and difficulty in phonological form selection at the level of phonological output representation [36].

McGregor (1994) believed that the semantic errors could be produced as a result of the retrieval difficulties at the lexeme-level. This means that the semantic errors could occur because of a failure to access the target phonological representation, and a semantically related word is activated instead [36]. Consequently, this study didn't provide decisive evidence about the exact location of children's lexical retrieval difficulties.

According to the results, children make less formal (phonological) errors than semantic errors, but there was a significant difference in the frequency of formal errors between the children with and without SLI. The children's formal errors are probably caused by difficulty in phonological processing or representation, while they appropriately access the semantic representation. Although phonological errors were infrequent, they did differentiate the children with SLI from the children with TLD. This finding is consistent with other data suggesting that many children with SLI have difficulty in tasks that emphasize on phonological processing. For example, children with SLI make more errors compared to their peers in the non-word repetition tasks $[37,38]$.

Children with and without SLI produce the same semantic, formal and other errors occurring in lemma, lexeme or both stages, but the errors in children with SLI are more frequent. We can conclude that as a result of the insufficient lexical development, the process of lexical access in both TLD and SLI group is similar.

\section{Conclusion}

We found the various naming errors in children, especially in children with SLI, but this data cannot be used to differentiate between the children with and without language disorders and further studies are required. However, determining the type of naming errors in children can be useful to plan appropriate assessments and interventions in developmental language disorders. The future research could investigate the effect of psycholinguistic factors on naming errors in children. Moreover, the naming skills could be compared in children with different language disorders.

\section{Ethical Considerations}

\section{Compliance with ethical guidelines}

This study was approved by the Ethics Committee of the University of Social Welfare and Rehabilitation Science (IR. USWR.REC.1394.223) and written informed consent was obtained from the parents of study participants.

\section{Funding}

The present study is a part of a $\mathrm{PhD}$ dissertation accomplished in the Department of Speech Therapy in the University of Social Welfare and Rehabilitation Sciences, Tehran. In addition, this research was supported by the Cognitive Sciences and Technologies Council (2340).

\section{Conflict of interest}

The authors certify that they have no affiliation with or involvement in any organization or entity with any financial, or non-financial in the subject matter or materials dismissed in this manuscript.

\section{References}

[1] Leonard LB. Children with specific language impairment and their contribution to the study of language development. Journal of Child Language. 2014; 41(1):38-47. [DOI:10.1017/S0305000914000130]

[2] Verhoeven L, van Balkom H. Classification of developmental language disorders: Theoretical issues and clinical implications. New York: Psychology Press; 2003.

[3] Tomblin JB, Records NL, Buckwalter P, Zhang X, Smith E, O'Brien M. Prevalence of specific language impairment in kindergarten children. Journal of Speech, Language, and Hearing Research. 1997; 40(6):1245-60. [DOI:10.1044/ jslhr.4006.1245]

[4] Foroodi Nejad F. Towards the identification of linguistic characteristics of specific language impairment in Persian. Edmonton, Alberta: University of Alberta; 2011.

[5] Shahmahmood TM, Jalaie S, Soleymani Z, Haresabadi F, Nemati P. A systematic review on diagnostic procedures for specific language impairment: The sensitivity and specificity issues. Journal of Research in Medical Sciences. 2016; 21:67. [DOI:10.4103/1735-1995.189648]

[6] Dockrell JE, Messer D, Rachel G. Patterns of naming objects and actions in children with word finding difficulties Language and Cognitive Processes. 2001; 16(2-3):261-86. [DOI:10.1080/01690960042000030]

[7] German DJ. Spontaneous language profiles of children with word-finding problems. Language, Speech, and Hearing 
Services in Schools. 1987; 18(3):217-230. [DOI:10.1044/01611461.1803.217]

[8] Messer D, Dockrell JE. Children's naming and word-finding difficulties: Descriptions and explanations. Journal of Speech, Language, and Hearing Research. 2006; 49(2):30924. [DOI:10.1044/1092-4388(2006/025)]

[9] Johnson CJ, Paivio A, Clark JM. Cognitive components of picture naming. Psychological Bulletin. 1996; 120(1):113-39. [DOI:10.1037/0033-2909.120.1.113] [PMID]

[10] Levelt WJ, Roelofs A, Meyer AS. A theory of lexical access in speech production. Behavioral and Brain Sciences. 1999; 22(01):1-38. [DOI:10.1017/S0140525X99001776] [PMID]

[11] McGregor KK, Friedman RM, Reilly RM, Newman RM. Semantic representation and naming in young children. Journal of Speech, Language, and Hearing Research. 2002. 45(2):332-46. [DOI:10.1044/1092-4388(2002/026)]

[12] Lahey M, Edwards J. Naming errors of children with specific language impairment. Journal of Speech, Language, and Hearing Research. 1999; 42(1):195-205. [DOI:10.1044/jslhr.4201.195]

[13] Kambanaros M, Grohmann KK. Patterns of object and action naming in Cypriot Greek children with SLI and WFDs. In: Franich L, Keil K, Iserman J, editors. Proceedings of the $34^{\text {th }}$ Boston University Conference on Language Development; Boston: Linguistics Department; 2010.

[14] Windfuhr G. The Iranian Languages. New York: Psychology Press; 2009.

[15] Karimi H, Nilipour R. [Characteristics of developmental stuttering in Iran (Persian)]. Multilingual Aspects of Fluency Disorders. 2011; 5:205-7.

[16] Kazemi Y, Saeednia S. The clinical examination of nonword repetition tasks in identifying Persian-speaking children with primary language impairment. International Journal of Pediatric Otorhinolaryngology. 2017; 93:7-12. [DOI:10.1016/j.ijporl.2016.11.028] [PMID]

[17] Karami A. [Child intelligence measurement (Raven children's test) (Persian)]. Tehran: Ravansanji; 2016.

[18] Hasanzadeh S, Minaii A. [Adaptation and standardization of the test of TOLD-P: 3 for Farsi-speaking children of Tehran (Persian)]. Journal of Exceptional Children. 2002; 1(2):119-34.

[19] Nilipour R. [Persian test of specific language impairment (Persian)]. Tehran: University of Social Welfare and Rehabilitation Sciences; 2002.

[20] Nilipour RG, Karimi Javan G, Ghoreishi ZS. [Predictors of quality of speech and slow information processing in Persian children with Special Language Impairment (SLI) (Persian)]. Journal of Exceptional Children. 2017; 15(2): 67-77.

[21] Hassanati F, Nilipour R, Ghoreish ZS, Pourshahbaz A, Momenian M. [The effect of psycholinguistic factor on picture naming in Persian speaking children (Persian)]. International Journal of Children and Adolescent. 2017; 3(4):13-21.

[22] Forster KI, Forster JC. DMDX: A windows display program with millisecond accuracy. Behavior Research Methods, Instruments \& Computers. 2003; 35(1):116-24. [DOI:10.3758/BF03195503]
[23] D’Amico S, Devescovi A, Bates E. Picture naming and lexical access in Italian children and adults. Journal of $\mathrm{Cog}$ nition and Development. 2001; 2(1):71-105. [DOI:10.1207/ S15327647JCD0201_4]

[24] Bakhtiar M, Nilipour R, Weekes BS. Predictors of timed picture naming in Persian. Behavior Research Methods. 2013; 45(3):834-41. [DOI:10.3758/s13428-012-0298-6] [PMID]

[25] Dell GS, Schwartz MF, Martin N, Saffran EM, Gagnon DA. Lexical access in aphasic and nonaphasic speakers. Psychological Review. 1997; 104(4):801-38. [DOI:10.1037/0033295X.104.4.801] [PMID]

[26] Leonard LB, Nippold MA, Kail R, Hale CA. Picture naming in language-impaired children. Journal of Speech Language, and Hearing Research. 1983; 26(4):609-15. [DOI:10.1044/jshr.2604.609]

[27] Sheng L. Lexical access and semantic organization in children with specific language impairment [PhD desertation]. Evanston, Illinois: Northwestern University; 2007.

[28] Lahey M, Edwards J. Why do children with specific language impairment name pictures more slowly than their peers? Journal of Speech, Language, and Hearing Research. 1996; 39(5):1081-98. [DOI:10.1044/jshr.3905.1081]

[29] Montgomery JW, Scudder RR, Moore CA. Languageimpaired children's real-time comprehension of spoken language. Applied Psycholinguistics. 1990; 11(3):273-90. [DOI:10.1017/S0142716400008894]

[30] McGrego KK, Appel A. On the relation between mental representation and naming in a child with specific language impairment. Clinical Linguistics \& Phonetics. 2002; 16(1):120. [DOI:10.1080/02699200110085034]

[31] Alt M, Plante E. Factors that influence lexical and semantic fast mapping of young children with specific language impairment. Journal of Speech, Language, and Hearing Research. 2006; 49(5):941-54. [DOI:10.1044/10924388(2006/068)]

[32] McGregor KK. The nature of word-finding errors of preschoolers with and without word-finding deficits. Journal of Speech, Language, and Hearing Research. 1997; 40(6):123244. [DOI:10.1044/jslhr.4006.1232]

[33] McGregor KK, Waxman SR. Object naming at multiple hierarchical levels: A comparison of preschoolers with and without word-finding deficits. Journal of Child Language. 1998; 25(02):419-30. [DOI:10.1017/S030500099800347X] [PMID]

[34] Katz WF, Curtiss S, Tallal P. Rapid automatized naming and gesture by normal and language-impaired children. Brain and Language. 1992; 43(4):623-41. [DOI:10.1016/0093934X(92)90087-U]

[35] McGregor KK, Newman RM, Reilly RM, Capone NC. Semantic representation and naming in children with specific language impairment. Journal of Speech, Language, and Hearing Research. 2002; 45(5):998-1014. [DOI:10.1044/10924388(2002/081)]

[36] McGregor KK. Use of phonological information in a word-finding treatment for children. Journal of Speech, Language, and Hearing Research. 1994; 37(6):1381-93. [DOI:10.1044/jshr.3706.1381] 
[37] Edwards J, Lahey M. Nonword repetitions of children with specific language impairment: Exploration of some explanations for their inaccuracies. Applied Psycholinguistics. 1998; 19(2):279-309. [DOI:10.1017/S0142716400010079]

[38] Gathercole SE, Baddeley AD. Phonological memory deficits in language disordered children: Is there a causal connection? Journal of Memory and Language. 1990; 29(3):33660. [DOI:10.1016/0749-596X(90)90004-J] 